\title{
Polytene Chromosome aberrations based Genotoxicity evaluation of Dichlorvos insecticide using Drosophila malenogaster
}

\author{
Lovleen* and Ishrat Kashafi \\ School of Bioengineering and Biosciences, Lovely Professional University, \\ Phagwara-144410, India
}

\begin{abstract}
Present research work deals with evaluation of clastogenic and cytotoxic effects of Dichlorvos using larval salivary gland polytene chromosomes of Drosophila melanogaster. Exposure limit, $\mathrm{LC}_{20}$, was standardized by considering mortality of second instar larvae exposed to serial dilution of selected insecticide, for 24 hours. Subsequently, third instar larvae were sacrificed for temporary squash preparation of polytene chromosome, along with controls. The structural chromosomal aberration in treated stocks were incidences of ectopic pairings, paracentric inversions, chromatid breaks, chromosomal fusions, asynapses and

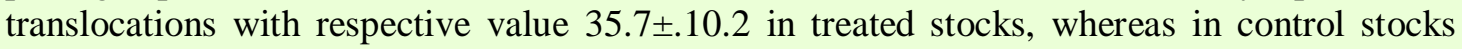
predominant chromosomal aberrations were, paracentric inversions, chromosomal fusions and ectopic pairings with corresponding value $14.5 \pm 5.21$. Statistical analysis indicated that Dichlorvos induced significant genotoxicity in exposed larvae in comparison to control.

Key words : Genotoxicity evaluation, Dichlorvos, Polytene chromosomes, Drosophila melanogaster.
\end{abstract}

\section{Introduction and Experimental}

Excessive implication of pesticides has escalated food production for rapid growing population but simultaneously, such formulations have caused drastic consequences to biotic and biotic components of an ecosystem. Pesticide toxicity has ultimately resulted in diverse acute and chronic consequences like mild headache, flu, skin rashes, nausea, dizziness, diarrhoea, hormonal imbalance, immune suppression, diminished intelligence, genetic disorders, cancer, fertility problems, birth defects, miscarriages, leukaemia, non-Hodgkin's lymphoma, hormonal changes, liver damage, kidney disease, suppression of the immune system, asthma, allergic dermatitis, respiratory complications, auto-immune, neurological and behavioural disorders ${ }^{1-30}$. Therefore, the genotoxicity evaluation and mutagenicity testing of the such chemicals has become crucial aspect, before their commercial applications. Motivated by particular reason, present research execution has been carried out that deals with genotoxicity of Dichlorvos (2,2 dichlorovinyl dimethyl phosphate)insecticide using genetic component of Drosophila melanogaster. 
Drosophila melanogaster is widely used as test model for various investigations related with genotoxicity evaluation of different mutagens, through suitable methodologies. For present genotoxicity evaluation, Dichlorvos has been selected due to its broad spectrum insecticidal properties and its excessive applications in agricultural fields in Jalandhar district. Dichlorvos, a contact and stomach insecticides, is widely used to control insects in agricultural fields, building and outdoor areas. Concerned chemical is used against aphids, spider, mites, caterpillars, thrips and whiteflies in greenhouse, on fruit and vegetable crops. This insecticide acts on acetylcholinestrase enzyme associated with nervous system. Acute symptoms appear after exposure of chemical includes weakness, headache, and tightness in chest, blurred vision, salivation, sweating, nausea, vomiting, diarrhoea, and abdominal cramps.

In present research execution clastogenic and mutagenic properties of Dichlorvos is determined at sub lethal concentration, which is usually much less than the exposure limit, actually applied in fields. Exposure of selected dose was given to second instar larvae, subsequently insecticide exposed larvae were reared unto third instar larvae, which were sacrificed to prepare temporary squash preparation of polytene chromosomes. Good quality of chromosomes compliments with proper spreading and distinct banding pattern, were selected for photography. Subsequently, obtained data was analysed for various types of chromosomal aberrations in insecticide exposed groups and natural population. Scrutinized number of chromosomal aberrations in treated stock was compared with that of control population. Subsequently, procured data from insecticide exposed group was compared with control stock and statistical analysis was done, which indicated statistically significant induced genotoxicity.

\section{Test organism and Rearing of larvae:}

For present research execution, Drosophila melanogaster is selected as test model because of its easy adaptability to laboratory conditions, short life span, small diploid number $(2 n=8)$, and presence of polytene chromosomes. Initial population of Drosophila melanogaster was obtained from, Drosophila breeding laboratory, Department of Biotechnology, Punjab Agricultural University, Ludhiana. Culturation of Oregon strain of Drosophila melanogaster was executed in BOD incubator set at $25 \pm 1{ }^{0} \mathrm{C}$. The culture medium for rearing was prepared by mixing agar, yeast, maize powder and brown sugar in cultural vials. The medium was kept hydrated for easy movement of larvae and kept away from dirt, direct sunlight and other heat sources.

\section{Information about chemical :}

For present genotoxicity, an organophosphate pesticide Dichlorvos, has been investigated and concerned formulation is a broad spectrum organophosphate insecticide, with IUPAC Name, 2,2-dichlorovinyl dimethyl phosphate, Molecular formula $\mathrm{C}_{4} \mathrm{H}_{7} \mathrm{Cl}_{2} \mathrm{O}_{4} \mathrm{P}$ (Figure 1) ${ }^{31}$, available under trade name DDVP (Swal CoOperation Limited, Mumbai). For present research work, a packet of $100 \mathrm{ml}$ was purchased from market, was used as such because primary motive of research is to check genotoxicity of formulation which is actually going to fields.

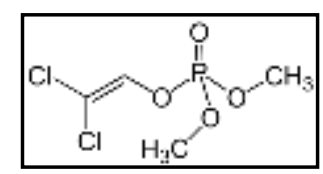

Figure 1: Chemical structure of Dichlorvos



Figure2: Regression line between concentration of exposure of Dichlorvos and probit of kill of Drosophila melanogaster 


\section{Standardization of exposure concentration:}

Sub lethal concentration, $\mathrm{LC}_{20}$ was taken as a suitable concentration for the present set of experiments. In order to standardize exposure concentration, second instar larvae were kept for 24 hours in serial dilutions of stock solution of selected insecticide. For each set, twenty larvae were kept and three replicates of them were maintained. After 24 hours, the mortality of larvae was reported and exact value of $\mathrm{LC}_{20}$ was calculated separately applying probit analysis ${ }^{32-34}$, which was $1.99 \mathrm{pl} / \mathrm{ml}$ (Figure 2) for Dichlorvos on Drosophila melanogaster.

\section{Exposure to selected concentration to larvae and methodology:}

The exposure of the insecticide Dichlorvos was given by mixing the concerned insecticide with the cultural medium. Subsequently, third instar larvae were sacrificed to prepare temporary squash preparation of polytene chromosomes. For slide preparation, healthy and active third instar larvae were dissected in $0.67 \%$ saline and two bilobed salivary glands (Figure 3) were taken out by splitting the thorax region. Staining had been carried out in $2 \%$ lactoorcein stain by following standardized staining technique with suitable modification ${ }^{35-37}$. The slides with well spread chromosomes were immediately studied and photographed under suitable magnification. Only the chromosomal compliment with well spread chromosomes and desirable staining were selected for photography (Figure 4). The well spread chromosomal compliments from the temporary squash were counted and scrutinized for chromosomal aberrations.

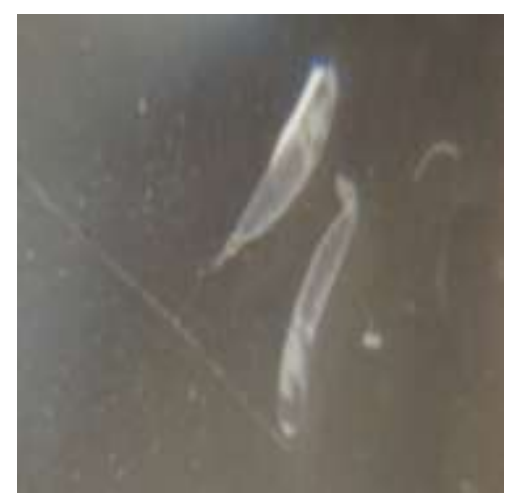

Figure 3: Bilobed larval salivary gland of Drosophila melanogaster

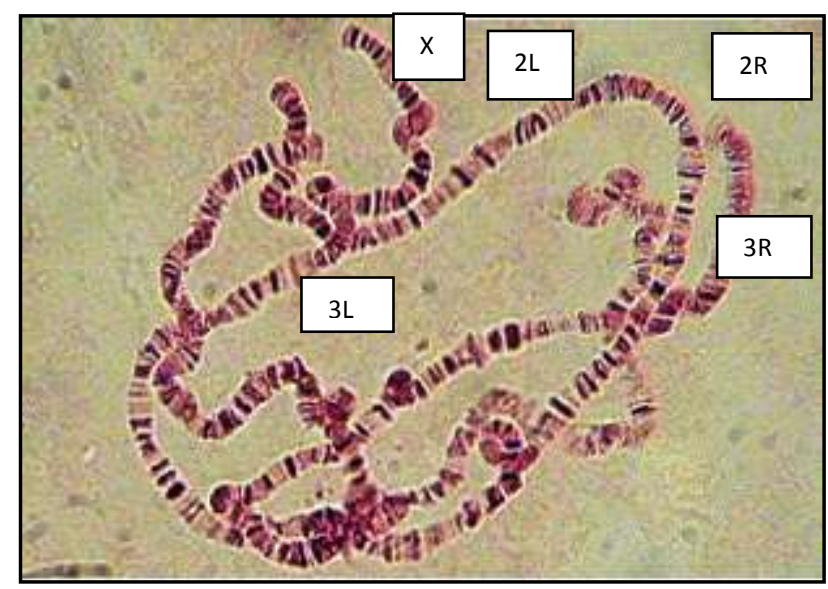

Figure 4: Normal Chromosomal compliment of polytene chromosomes with chromocenter and different arms radiating out from it. 


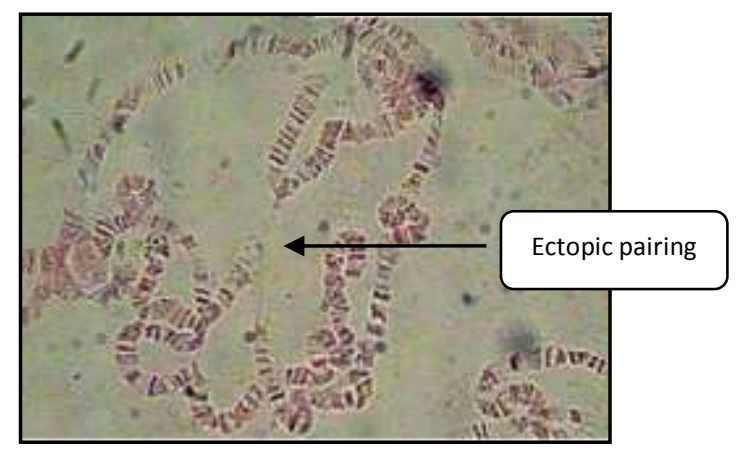

Figure 5: Interchromosomal ectopic pairing in polytene chromosomes

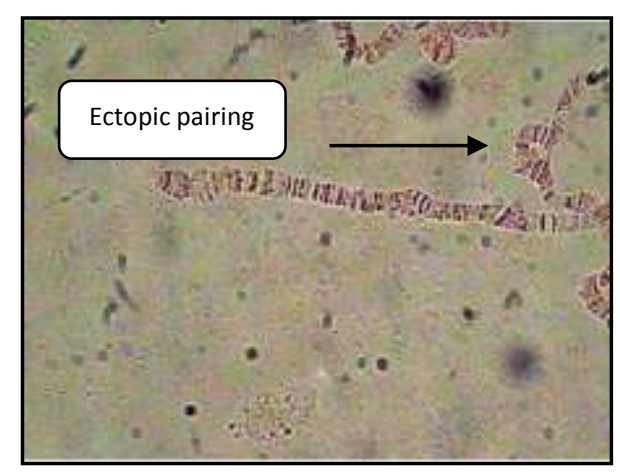

Figure 6: Intrachromosomal ectopic pairing in polytene chromosomes



Figure 7: Intrachromosomal ectopic pairing in polytene chromosomes

\section{Data Analysis:}

Subsequently, procured data was scrutinized for various types of chromosomal aberrations including hyper condensed area, incidences of ectopic pairings (Figure 5-7), paracentric inversions (Figure 8), chromatid breaks, chromosomal fusions (Figure 9), asynapses and translocations. Mean, standard deviation and the statistical analysis of the chromosomal aberrations in treated stock were carried out and were compared with that of the control groups (Table 1).

Table 1: Statistical analysis of chromosomal aberration in Dichlorvos treated and control stocks.

\begin{tabular}{|l|l|l|l|l|l|l|l|l|}
\hline Type & $\begin{array}{l}\text { Ectopic } \\
\text { pairing } \\
\text { Mean } \pm \text { SD. }\end{array}$ & $\begin{array}{l}\text { Inversions } \\
\text { Mean } \pm \text { S.D. }\end{array}$ & $\begin{array}{l}\text { Breaks } \\
\text { Mean } \pm \text { S. } \\
\text { D. }\end{array}$ & $\begin{array}{l}\text { Fusions } \\
\text { Mean } \pm \text { S.D }\end{array}$ & $\begin{array}{l}\text { Asynapsis } \\
\text { Mean } \pm \text { S.D. }\end{array}$ & $\begin{array}{l}\text { Translocatio } \\
\text { ns } \\
\text { Mean } \pm \text { S.D. }\end{array}$ & $\begin{array}{l}\text { Total } \\
\text { Mean } \pm \text { S.D. }\end{array}$ & $\begin{array}{l}\mathbf{t} \\
\text { value }\end{array}$ \\
\hline Treated & $13.3 \pm 2.3$ & $7.5 \pm 1.8$ & $5 \pm 1.41$ & $4 \pm 2$ & $3.3 \pm 1.14$ & $2.6 \pm 1.61$ & $35.7 \pm .10 .2$ & \\
\hline Control & $3 \pm 1.41$ & $7.5 \pm 1.8$ & -- & $4 \pm 2$ & -- & -- & $14.5 \pm 5.21$ & 2.8 \\
\hline
\end{tabular}

S.D = standard deviation

Degree of freedom $=4$

$*_{\mathrm{p}}<0.05$ 


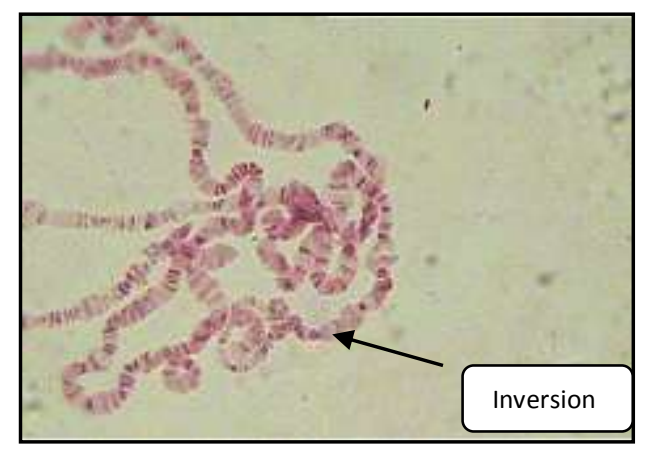

Figure 8: Paracentric inversion in polytene chromosomes

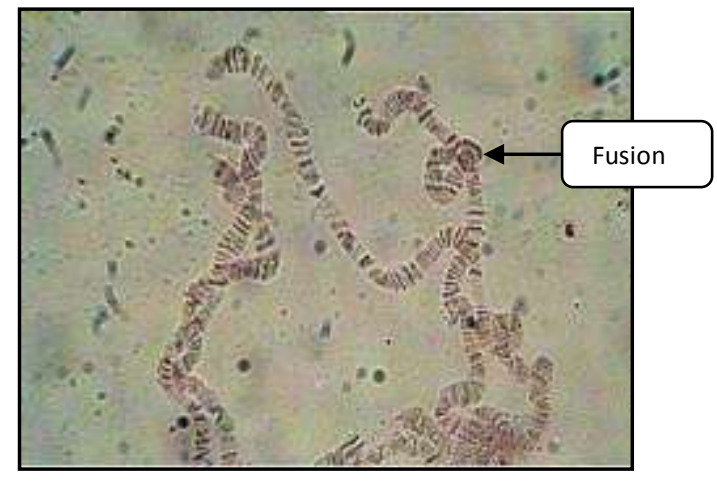

Figure 9: Chromosomal fusion in polytene chromosomes

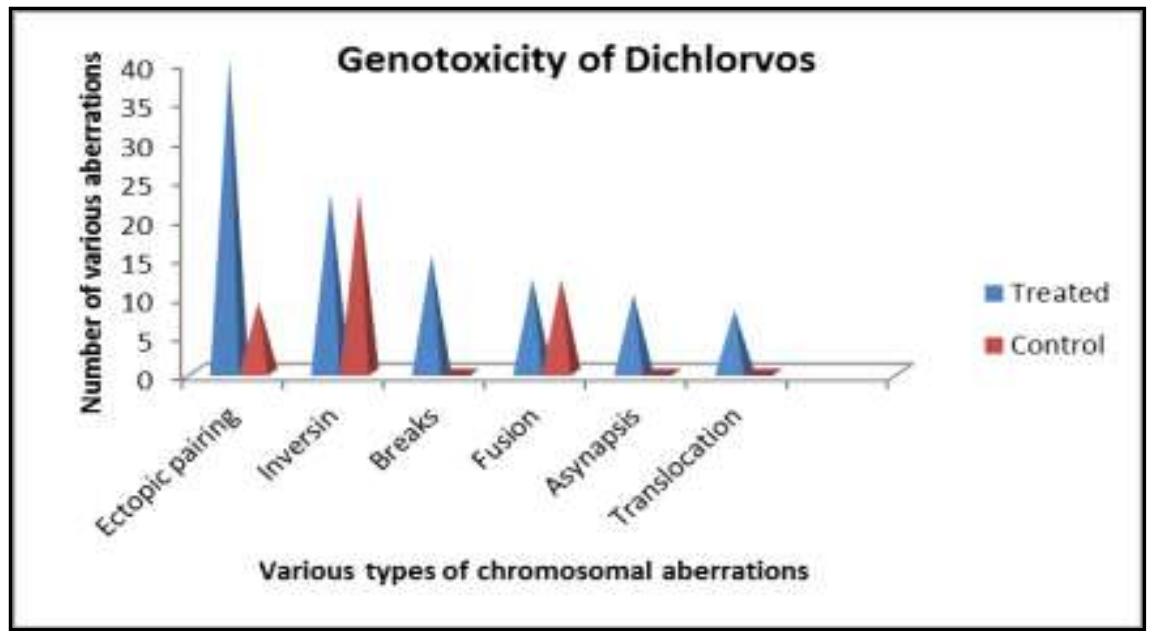

Figure 10: Graphical depiction of genotoxicity induced by Dichlorvos insecticide in salivary polytene chromosomes of Drosophila melanogaster. The concerned insecticide induced maximum ectopic pairings, followed by inversions, breaks, fusions, asynapses and translocation. Not even a single incidence of chromosomal break, asynpases and translocation had been reported in control stocks.

\section{Results and Discussion}

Present study is about toxicity induced by selected insecticide on structural integrity of larval salivary polytene chromosomes, at sublethal concentration. $\mathrm{LC}_{20}$ was standardized by giving exposure serial dilution of selected herbicide to second instar larvae, and subsequently on the basic of caused mortality, exact value of $\mathrm{LC}_{20}$ was calculated. Larval salivary polytene chromosomes were securitized for various chromosomal malformation and it was reported that Dichlorvos effected the structural organization of polytene chromosomes by causing incidences of ectopic pairings, paracentric inversions, chromatid breaks, chromosomal fusions, asynapses and translocations, which correspond to number 40,23,1512,10 and 8 in treated stocks, whereas in control stocks predominant chromosomal aberrations were, inversions, chromosomal fusions and ectopic pairings with respective value 23, 15 and 9 (Figure 10). It was further observed that mutagenic instrinct of 
selected insecticide was expressed in the form of ectopic pairings, followed by inversion, chromatid breaks and fusion. Not even a single incidence of asynapsis and translocation was reported in control groups.

During present research execution, clastrogenic instinct of Dichlorvos, has been observed in the form of various structural chromosomal abnormalities. Predominantly, incidences of intrachromosomal and interchromosomal ectopic pairings were reported. Scientific literature review suggested that mutagens which affect the structural integrity of genetic material cause ectopic pairings. Numerous investigation indicated that in polyene chromosomes of different organisms including Chironomus acidophilus, Chironomus riparius and Glyptotendipes salinus exposed to different concentrations of trace metals like $\mathrm{Al}, \mathrm{Cr}, \mathrm{Pb}$ and $\mathrm{Cu}$, incidences of ectopic pairings were there, as expression of abnormal interaction of different mutagens ${ }^{38-41}$. The incidence of ectopic pairings was dependent on the organization of the genome in the polytene chromosomes of an organism and interspersed repetitive $\mathrm{DNA}^{42}$. Furthermore, enhanced number of paracentric inversions, were also very common chromosomal malformation during present investigation. Various mutagens generally induced different type of aberrations in the genetic material by inducing breaks in it. Sometimes, the broken segment tends to rotate by $180^{\circ}$ and gets reinserted in the same place before the repair can take place, which ultimately produces inversions. Such types of aberration generally occur by effects of environmental mutagen on weak points. It was found that various environmental pollutants were responsible for inversions in the polytene chromosomes of naturally inhabiting species of Chironomus, as a expression of induced genotoxicity due to traces of certain heavy metals and radio nuclids ${ }^{43}$ whereas in an another study, it was concluded that in several species of Chironomus, most of the somatic chromosome rearrangements occur more frequently in the specific regions of the chromosomes which are composed of repetitive DNA loci ${ }^{44}$.During present set of experiments chromosomal fusion and chromosomal beaks along with asynapses of homologues and translocation has also been observed in insecticide exposed group.For chromosomal fusion, an investigator offered a new perspective about this type of chromosomal change which, according to him, arose due to chromosomal stickiness and breakage. A hypothesis consistent with this claim states that chromosome stickiness results from changes in specific nonhistone proteins such as topoisomerase II and the peripheral proteins which form integral components of the chromosomes ${ }^{45}$. One another study also claimed the role of certain proteins in the process of chromosomal fusions in Drosophila in which a separate class of proteins helped in the repair of telomeric breaks which arose after exposure to mutagens ${ }^{46}$. Infact, increased frequency of Asynapsis in polytene chromosomes is also a manifestation of induced genotoxicity due to the mutagenic agents. Studies carried out so far relate this aberration to the denaturing of the binding proteins due to the action of chemicals. For instance, in one of investigation, it was observed that the incidents of asynapses were more in polytene chromosomes of mosquito larvae treated with lead and mercury than in their control stocks ${ }^{47}$ whereas according to some other research explorations, it was reported that induced asynapsis in the polytene chromosomes of Glyptotendipe barbipes occur due to polymorphism in those regions of the chromosomes which had structural heterozygosity ${ }^{48-49}$. Later, while studying the position of alcohol dehydrogenase genes in the polytene chromosomes of Drosophila melanogaster, it was found that different breakpoints responsible for various deficiencies arose in those chromosomes which were under replication ${ }^{50}$. In a study about the mechanism of the repair of breaks in $D$. Melanogaster, it was found that proliferating cell nuclear antigens (PCNA) in the proliferating cells were somehow related with the eukaryotic replication factors essential for repair of DNA double-strand breaks (DSBs) and lesions arising due to the action of mutagens ${ }^{51}$.

Few reports about genotoxicity of Dichlorvos are also available in scientific literature as it was observed that Dichlorvos caused cholinergic neurological symptoms in Sherman rats ${ }^{52}$ whereas in another study,it was observed that Dichlorvos effect kidneys as well as reproductive organs in male rat $^{53}$. One more investigation conducted on mice, indicated that, Dichlorvos acted as cancerogen ${ }^{54}$ whereas inanother study, it was observed that concerned chemical caused chromosomal aberrations in the form of centromeric gaps, chromatid gaps, chromatid breaks, sub-chromatid breaks, attenuation, extra fragments, pycnosis, stubbed arms in kidney cells of Channa punctatus ${ }^{55}$. Similarly, Dichlorvos was observed to cause alteration in DNA replication, which resulted mutation and cellular hyper proliferation ${ }^{56}$ interestingly, there was an inverse relationship between duration of exposure and aberration frequency. Longer exposures to Dichlorvos were associated with lower frequencies of aberrations. Genotoxic properties of this insecticide, is also documented by few more studies ${ }^{57-58}$ Dichlorvos was reported as possible mutagen, when assessed through Ames test ${ }^{59}$, and furthermore, Dichlorvos was analysed to induce sister chromatid exchange and chromosomal aberrations in Chinese hamster ovary $(\mathrm{CHO})$ cell line ${ }^{60}$. 


\section{Concluding remarks:}

During present study also, genotoxicity of Dichlorvos has also been reported at sublethal concentration on Drosophila melanogaster. The abnormal interaction of Dichlorvos had been observed in the form of various structural malformations, predominantly ectopic pairing followed by paracentric inversions, chromatid breaks, chromosomal fusions, asynapses and translocations. Furthermore, analysis of mutagenic instrict of Dichlorvos is suggested at intensive level, alternatives of pesticides should be implemented, and use of natural predators of target pests should also be considered.

\section{Acknowledgement}

Authors are very thankful to Management of Lovely Professional University, Phagwara for providing required support for present research execution.

\section{References}

1. H.J. Muller, Entomological Soc. Am. Bull., 9, 173 (1927).

2. K. Sax, Genetics, 23, 494 (1938).

3. A.J. Wyrobek, G. Watchmaker, L. Gordon, K. Wong, D. Moore and D. Whorton, Environ. Health Perspect., 40, 255 (1981); doi:10.1289/ehp.8140255.

4. A. Onfelt and I. Klasterska, Mutat. Res., 125, 269 (1984); doi:10.1016/0027-5107(84)90076-9.

5. P. Ghosh, S. Bhattacharya and S. Bhattacharya, Biomed. Environ. Sci., 3, 106 (1990).

6. M. Restrepo, N. Munoz, N. Day, J.E. Parra, C. Hernandez, M. Blettner and A. Giraldo, Environ. Health, 16, 239 (1990).

7. S.A. Rotenberg and I.B. Weinstein, Mol. Carcinog., 4, 477 (1991); doi:10.1002/mc.2940040611.

8. J.R. Davis, R.C. Brownson and R. Garcia, Arch. Environ. Contam. Toxicol., 22, 206 (1992); doi:10.1007/BF00212083.

9. B. Baranski, Environ. Health Perspect., 101(Suppl 2), 81 (1993); doi:10.1289/ehp.93101s281.

10. E. Zuskin, E. Neil Schachter and J. Mustajbegovic, Int. Arch. Occup. Environ. Health, 64, 521 (1993); doi:10.1007/BF00381102.

11. J. Decock, K. Westveer, D. Heederik, E.R. Tevelde and R.J. Vankooij, Occup. Environ. Med., 51, 693 (1994); doi:10.1136/oem.51.10.693.

12. L.J. Guillette, T.S. Gross, G.R. Masson, J.M. Matter, H.F. Percival and A.R. Woodward, Environ. Health Perspect., 102, 680 (1994); doi:10.1289/ehp.94102680.

13. I. Aguirrezabalaga, I. Santamaría and M.A. Comendador, Mutagenesis, 9, 341 (1994); doi:10.1093/mutage/9.4.341.

14. S.B. Nath, S. Raju, R.P.G. Krishna and S.R.P. Kumar, J. Environ. Biol., 17, 269 (1996).

15. U.C. Jadaramkunti and B.B. Kaliwal, J. Basic Clin. Physiol. Pharmacol., 10, 305 (1999).

16. E. Tielemans, R. van Kooij, E.R. te Velde, A. Burdorf and D. Heederik, Lancet, 354, 484 (1999); doi:10.1016/S0140-6736(99)00599-1.

17. G. Petrelli, I. Figatalamanca, R. Tropeano, M. Tangucci, C. Cini, S. Aquilani, L. Gasperini and P. Meli, Eur. J. Epidemiol., 16, 391 (2000); doi:10.1023/A:1007630610911.

18. A. Rojas R, M.E. Ojeda B and X. Barraza O, Rev. Med. Chil., 128, 399 (2000); doi:10.4067/S0034$\underline{98872000000400006}$.

19. J.L. Daniels, A.F. Olshan, K. Teschke, I. Hertz-Picciotto, D.A. Savitz, J. Blatt, M.L. Bondy, J.P. Neglia, B.H. Pollock, S.L. Cohn, A.T. Look, R.C. Seeger and R.P. Castleberry, Epidemiology, 12, 20 (2001); doi:10.1097/00001648-200101000-00005. 
Lovleen et al/International Journal of PharmTech Research, 2017,10(2): 74-82.

20. U.C. Jadaramkunti and B.B. Kaliwal, J. Basic Clin. Physiol. Pharmacol., 12, 217 (2001); doi:10.1515/JBCPP.2001.12.3.217.

21. U.C. Jadaramkunti and B.B. Kaliwal, Bull. Environ. Contam. Toxicol., 69, 741 (2002); doi:10.1007/s00128-002-0123-5.

22. C.K. Grisolia, Mutat. Res., 518, 145 (2002); doi:10.1016/S1383-5718(02)00086-4.

23. J.M. Kiesecker, Proc. Natl. Acad. Sci. USA, 99, 9900 (2002); doi:10.1073/pnas.152098899.

24. D.M. Schreinemachers, Environ. Health Perspect., 111, 1259 (2003); doi:10.1289/ehp.5830.

25. K.N.M. Maclellan, D.M. Bird, D.M. Fry and J.L. Cowles, Arch. Environ. Contam. Toxicol., 30, 364 (1996); doi:10.1007/BF00212295.

26. R.A. Cassidy, S. Natarajan and G.M. Vaughan, Breast Cancer Res. Treat., 90, 55 (2005); doi:10.1007/s10549-004-2755-0.

27. A. Chaudhry, P.K. Anand, Geeta, S. Singh and Lovleen, Cytologia (Tokyo), 71, 431 (2006); doi:10.1508/cytologia.71.431.

28. A. Chaudhry and Lovleen, J. Cytology Genetics, 9, 37 (2008).

29. Lovleen, Res. J. Pharm., Biol. Chem. Sci., 6, 339 (2015c).

30. Lovleen, Int. J. Pharma Bio. Sci., 6, 744 (2015d).

31. https://pubchem.ncbi.nlm.nih.gov/compound/dichlorvos\#section=Top.

32. D.J. Finney, Probit analysis, Cambridge University Press, Cambridge, Vol. 3, pp. 237-245 (1971).

33. A. Chaudhry and Lovleen, J. Cytol. Genetics, 11, 11 (2010).

34. P. Bhinder and A. Chaudhry, Toxicol. Int., 20, 254 (2013); doi:10.4103/0971-6580.121678.

35. W.L. French, R.H. Baker and J.B. Kitzmiller, Mosq. News, 22, 377 (1962).

36. Lovleen, Asian J. Pharmacol. Toxicol., 3, 1 (2015a).

37. Lovleen, J. Chem. Pharm. Res., 7, 533 (2015b).

38. P. Michailova, N. Petrova, L. Ramella, G. Sella, J. Todorova and V. Zelano, Genetica, 98, 161 (1996); doi:10.1007/BF00121364.

39. P. Michailova, N. Petrova, S. Bovero, M. Cavicchioli, L. Ramella and G. Sella, Genetica, 108, 171 (2000); doi:10.1023/A:1004172019131.

40. P. Michailova, N. Petrova, J. Ilkova, S. Bovero, S. Brunetti, K. White and G. Sella, Environ. Pollut., 144, 647 (2006); doi:10.1016/j.envpol.2005.12.041.

41. J. Ilkova, T. Hankeln, E. Schmidt, P. Michailova, N. Petrova, G. Sella and K. White, Caryologia, 60, 299 (2007); doi:10.1080/00087114.2007.10797951.

42. P. Michailova, K. Todorova and K. White, Biologia, 57, 359 (2002).

43. L. Gavrila, L. Burlibasa, M.D. Usurelu, I. Radu, L.M. Magdalena, A. Ardelean and M. Carabas, Rom. Biotechnol. Lett., 13, 3962 (2008).

44. P.V. Michailova, Botuc., 14, 43 (2010).

45. M.E. Gaulden, Mutagenesis, 2, 357 (1987); doi:10.1093/mutage/2.5.357.

46. A. Purdy and T.T. Su, Curr. Biol., 14, R613 (2004); doi:10.1016/j.cub.2004.07.042.

47. G.P. Sharma and S. Chaudhry, Cytologia (Tokyo), 41, 733 (1976); doi:10.1508/cytologia.41.733.

48. P. Michailova and P. Belcheva, Folia Biologica, 38, 83 (1990).

49. P. Michailova, K. Todorova and K. White, Folia Biologia, 57, 359 (2002).

50. R.C. Woodruff and M. Ashburner, Genetics, 92, 117 (1979). 
51. D.S.Henderson and D.M.Glover, Mutagenesis, 13, 57 (1998); doi:10.1093/mutage/13.1.57.

52. W.F. Durham, T.H.B. Gaines and W.J. Hayes, Health, 13, 326 (1956).

53. D. Blair, Genetics, 92, 117 (1969).

54. D.J. Benford, S.C. Price, J.N. Lawrence, P. Grasso and J.N. Bremmer, Toxicology, 92, 203 (1994); doi:10.1016/0300-483X(94)90178-3.

55. K.K. Rishi and S. Grewal, Mutat. Res., 344, 1 (1995); doi:10.1016/0165-1218(95)90032-2.

56. J.C. Mirsalis, C.K. Tyson, K.L. Steinmetz, E.K. Loh, C.M. Hamilton, J.P. Bakke and J.W. Spalding, Environ. Mol. Mutagen., 14, 155 (1989); doi:10.1002/em.2850140305.

57. G. Cabrera, Environ. Mol. Mutagen., 36, 206 (2000); doi:10.1002/1098-2280(2000)36:3<206::AIDEM4>3.0.CO;2-U.

58. Y.F. Sasaki, K. Sekihashi, F. Izumiyama, E. Nishidate, A. Saga, K. Ishida and S. Tsuda, Crit. Rev. Toxicol., 30, 629 (2000); doi:10.1080/10408440008951123.

59. T.C.Wang, Lin Chih-Min and Lo Li-Wen, Zoological Studies, 42, 462 (2003).

60. D.J. Brusick, V.F. Simmon, H.S. Rosenkranz, V.A. Ray and R.S. Stafford, Mutat. Res., 76, 169 (1980); doi:10.1016/0165-1110(80)90009-3. 